\title{
1 Isolation and characterisation of eight polymorphic \\ 2 microsatellite markers from South American limpets \\ 3 of the species complex Nacella
}

4 Kevin Pöhlmann and Christoph Held

5 Alfred-Wegener-Institute for Polar and Marine Research,

$6 \quad$ P.O. Box 12 0161, 27515 Bremerhaven, Germany

7 e-mail: Kevin.poehlmann@awi.de

Abstract

11 In this study we provide eight polymorphic microsatellite markers for the two South 12 American patellogastropods Nacella magellanica and N. deaurata. Microsatellite amplification was carried out in multiplex PCRs, a new feature of the program pipeline STAMP. Allelic diversity ranged from 5 to 57 alleles per locus. Observed heterozygosities varied between 0.1 and 0.98 . Three of the four loci designed for $N$. magellanica cross amplified also with $N$. deaurata, and two loci vice versa. Six of the microsatellites successfully cross amplified with the two sister taxa $N$. mytilina and $N$. delicatissima. This set of microsatellites provides a suitable tool for population genetic purposes and can be of important help in identifying morphologically ambiguous Nacella individuals.

Keywords: Nacellidae, Population genetics, multiplex PCR, Patagonia, castal organism

Species of the family Nacella mainly inhabit coastal areas of Chilean and Argentinian coasts in Patagonia and Tierra del Fuego as well as on the Falkland Island, UK. These South American members of the family comprise the following nine species: Nacella clypeater (Lesson 1831), Nacella deaurata (Gmelin 1791), Nacella delicatissima (Strebel 1907), Nacella fuegiensis (Reeve 1855), Nacella flammea (Gmelin 1791), Nacella magellanica (Gmelin 1791), Nacella magellanica chiloensis (Reeve 1855), Nacella magellanica venosa (Reeve 1854) and Nacella mytilina (Helbling 1779). Criteria for classification into these species are all based on morphology, like shell shape and colour, radula morphology and tentacle pigmentation (see: Valdovinos and Rüth 2005). It is yet not clear whether this classification of the different morphotypes into species is supported on a genetic level or 
whether it is a cause of phenotypic plasticity. Several physiological studies were carried out and revealed differentiation between the two most conspicious members of the genus, the intertidal Nacella magellanica and the subtidal Nacella deaurata (Malanga et al. 2004, Malanga et al. 2005, Gonzalez et al. 2008). The first attempt to unravel genetic differences between members of Nacella was undertaken by de Aranzamendi et al. (2009) using the ISSR technique (Inter simple sequence repeats). The authors could successfully demonstrate significant amounts of genetic differenciation between the species Nacella magellanica, Nacella deaurata and Nacella mytilina. All other species mentioned above were identical with $N$. magellanica or $N$. deaurata and therefore considered as morphotypes instead of being true species. However, multiallelic approaches like ISSR suffer from their inapplicability in many population genetic statistical tests that require biallelic markers. Therefore we developed eight polymorphic microsatellite markers to provide a tool for comprehensive studies on population structure, gene flow and demographic and evolutionary history of patagonian limpets from the genus Nacella.

Microsatellite isolation was carried out with individuals of Nacella magellanica and Nacella deaurata from Bahia Laredo and Bahia Gregorio, both sites located in the Central Magellan Strait, Chile. Genomic DNA was isolated from muscle tissue preserved in Ethanol using spin columns (QIAGEN DNeasy Mini Kit), applying the standard tissue protocol. For each species enriched microsatellites genomic libraries were produced using the reporter genome protocol by Nolte et al. (2005), modified by Held and Leese (2007). Single stranded DNA from Mus musculus, bound to Hybridization chips (Hybond $\mathrm{N}+$, Healthcare), served as reporter genome probes. Enriched fragments were PCR-amplified, purified using the QIAGEN Qiaquick Kit and finally cloned into pCR2.1-TOPO vector and transformed into competent TOP10F' Escherichia coli (Invitrogen). After overnight growth in LB media positive clones were transfered to 96-well sequencing plates provided by GATC-Biotech (Konstanz, Germany) who also performed plasmid preparation of colonies and shotgun sequencing using a standard M13-forward primer.

Subsequent analyses of inserts containing microsatellites comprising vector clipping, redundancy detection and primer design were conducted using STAMP (Kraemer et al. 2009), a program pipeline based on the sequence analysis package STADEN (Staden 1996). Extensions to the basic program were the tandem repeat detection and analysis software PHOBOS (Mayer 2008 and the primer design program Primer 3 (Rozen and Skaletsky 2000). 
Only inserts containing microsatellites with a perfection of $95 \%$ or higher were chosen using phobos and considered for primer design.

For $N$. magellanica 14 redundant inserts were found in 79 sequenced clones. The remaining 65 unique inserts yielded 12 suitable loci, for which primers were designed using the multiplex option in PRIMER3 with a Tm of $55^{\circ} \mathrm{C}$. For $N$. deaurata 9 redundant inserts were found in 87 sequenced clones. The remaining 78 unique inserts resulted in 12 suitable loci. Also here the multiplex option was applied with a $\mathrm{Tm}$ of $55^{\circ} \mathrm{C}$. Primer pairs were tested on a gradient PCR over a variety of annealing temperatures ranging from $48^{\circ} \mathrm{C}$ to $65^{\circ} \mathrm{C}$. PCRs were carried out in total volume of $25 \mu 1$, containing $\sim 10 \mathrm{ng}$ genomic DNA, $0.2 \mathrm{~mm}$ dNTPs, $0.5 \mu \mathrm{m}$ primer, $0.5 \mathrm{~m}$ Betaine, $2.5 \mathrm{~mm} \mathrm{MgCl}, 0.03 \mathrm{U} / \mu \mathrm{L}$ Hotmaster Taq (Eppendorf). Following PCR conditions were applied: $2 \mathrm{~min} 94^{\circ} \mathrm{C}, 32$ cycles of $20 \mathrm{sec}$ at $94^{\circ} \mathrm{C}, 10 \mathrm{sec}$ at different annealing temperatures, $60 \mathrm{sec}$ at $65^{\circ} \mathrm{C}$ and a final extension of $45 \mathrm{~min}$ at $65^{\circ} \mathrm{C}$.

For N. magellanica, 10 of the 12 loci produced distinct PCR products, for $N$. deaurata 11 out of 12. These remaining 21 loci were chosen as candidate loci and fluorescent labelled primers were developed with the dyes HEX and FAM. PCRs were repeated as described above using the labelled primers. PCR products were purified using ExoSAPit (Fermentas). Exonuclease I (Exo) degradates remaining primers and Shrimp Alkaline Phophatase (SAP) inactivates remaining dNTPs. $5 \mu 1$ of PCR products were mixed with $0.25 \mu 1$ Exo I ( $20 \mathrm{U} / \mu 1)$ and $1 \mu 1$ $\mathrm{SAP}(1 \mathrm{U} / \mu \mathrm{l})$ and incubated at $37^{\circ} \mathrm{C}$ for $30 \mathrm{~min}$. Enzyme activities were subsequently inactivated by an incubation step of $15 \mathrm{~min}$ at $80^{\circ} \mathrm{C}$. The purified PCR products were denatured and analysed on an ABI 3130xl sequencer using ROX GS500 size standard (ABI). Genotyping was performed using the software genemapper 4.0.

For each species four microsatellite loci could be reliably genotyped. The remaining seven for $N$. magellanica and six for $N$. deaurata had to be excluded due to the presence of more than two alleles per individual or inconsistency during genotyping.

The remaining eight microsatellite loci were validated regarding their suitability for population genetic approaches. First the data were examined for possible scoring errors during the genotyping process using the software microchecker 2.2.3 (Van Oosterhout et al. 2004). Diversity measures and deviations from Hardy-Weinberg equilibrium were tested using the program Arlequin 3.11 (Exoffier et al. 2005) and tests for linkage disequilibrium were computed using genepop 4.0.6 (Rousset 2008). The unbiased probability of identity was calculated using gimlet 1.3.3 (Valiere 2002). Table 1 and 2 summarize the features of all eight polymorphic loci. Allelic diversity ranged from 5 (Nde3) to 57 (Nma6) alleles per locus. Observed heterozygosities varied between 0.1 
101 (Nde3) and 0.98 (Nde2). After Bonferroni correction (Rice 1989) Locus Nde8 deviated from

102 HWE $(\mathrm{p}<0.05)$ in the Falkland Population of Nacella deaurata and the Loci Nma6 and

103 Nma12 In the Central Magellan Population of Nacella magellanica. These deviations could

104 be caused by the presence of null alleles as suggested by microchecker. However, several

105 other explanations have to be taken into consideration such as inbreeding and population

106 expansion which also reduce heterozygosities in natural populations. No evidences for

107 scoring errors caused by large allelic dropout or stuttering could be found. Global linkage

108 disequilibrium analyses revealed no linkage between investigated Loci.

109

110 In addition, several cross amplification tests were carried out (Tab. 3). The four loci

111 developed for N. magellanica were cross tested with individuals of $N$. deaurata and vice

112 versa. Furthermore all eight loci were tested on the two nominal species N. mytilina and N.

113 delicatissima. Two of the loci developed for $N$. magellanica also work with the other three

114 species. Of the four loci developed for N. deaurata all work for N. mytilina and N.

115 delicatissima and three work with N. magellanica. Furthermore, these amplification patterns

116 enable us to correctly assign morphologically ambiguous specimens to the species they

117 belong to.

118 In total we developed and provide here eight polymorphic loci of which seven are appropiate

119 for population genetic studies with the South American limpets species N. magellanica and

120 six for the species $N$. deaurata, $N$. mytilina and $N$. delicatissima. These markers enable us to

121 develop a more profound classification of the genus Nacella and to study their evolutionary

122 and demographic history. 
Table 1: Genetic characterization of four polymorphic microsatellite loci isolated from individuals of Nacella deaurata collected on the Falkland Islands and the Central Magellan Strait region. $\mathrm{N}_{\mathrm{a}}$ Number of alleles, $\mathrm{T}_{\mathrm{a}}$ annealing temperature, $\mathrm{H}_{\mathrm{o}} / \mathrm{H}_{\mathrm{e}}$ observed and expected Heterozygosity, PI probability of identity. Violations of Hardy Weinberg Equilibrium are shown in bold numbers (Bonferroni corrected 5\% significant level $=0.00833$ )

\begin{tabular}{|c|c|c|c|c|c|c|c|c|c|c|c|c|}
\hline Locus & Primer sequence $\left(5^{\prime}-3^{\prime}\right)$ & Dye & repeat motif & $\mathbf{N}_{\mathrm{a}}$ & $\begin{array}{l}\text { Size } \\
\text { range } \\
\text { (bp) }\end{array}$ & $\begin{array}{c}\mathbf{T}_{\mathrm{a}} \\
\left({ }^{\circ} \mathbf{C}\right)\end{array}$ & $\mathbf{n}$ & $\mathbf{H}_{\mathbf{0}} / \mathbf{H}_{\mathrm{e}}$ & PI (unbiased) & $\mathbf{n}$ & $\mathbf{H}_{\mathbf{0}} / \mathbf{H}_{\mathrm{e}}$ & PI (unbiased) \\
\hline Nde1 & $\begin{array}{l}\text { F: TAT CAA CGC ATC TTT } \\
\text { CAT CA } \\
\text { R: CAC GAT GTG TTG AGG }\end{array}$ & Hex & $(\mathrm{GA})_{18}$ & 22 & $213-234$ & 57 & 52 & $0.92 / 0.89$ & $1.960 \times 10^{-2}$ & 39 & $0.97 / 0.95$ & $2.973 \times 10^{-3}$ \\
\hline Nde2 & $\begin{array}{l}\text { TGT AG } \\
\text { F: TAG GTG TTA CGA GGA } \\
\text { CGT TT } \\
\text { R: GAT CAA GAT TCA TCA } \\
\text { GTG GC }\end{array}$ & Fam & $(\mathrm{CT})_{18}(\mathrm{TC})_{7}$ & 25 & $154-218$ & 57 & 52 & $0.98 / 0.92$ & $7.703 \times 10^{-3}$ & 40 & $0.85 / 0.92$ & $6.515 \times 10^{-3}$ \\
\hline Nde8 & $\begin{array}{l}\text { F: TGT TGA TGA TGA AGG } \\
\text { TGA TG } \\
\text { R: AGA GAG GAG CTA AAC }\end{array}$ & Hex & $(\mathrm{GAG})_{6}(\mathrm{GAA})_{2}(\mathrm{GAG})_{3}$ & 19 & $108-151$ & 57 & 46 & $0.48 / 0.81$ & $4.133 \times 10^{-2}$ & 41 & $0.78 / 0.82$ & $4.471 \times 10^{-2}$ \\
\hline Nde3 & $\begin{array}{l}\text { CCA AT } \\
\text { F: TGA TTT AGA TAG GAG } \\
\text { AGC GG } \\
\text { R: AGG CTA AAT AAG CAT } \\
\text { TGT CG }\end{array}$ & Hex & $(\mathrm{AGAC})_{5}$ & 5 & $260-276$ & 57 & 52 & $0.1 / 0.13$ & $7.583 \times 10^{-1}$ & 42 & $0.12 / 0.11$ & $7.788 \times 10^{-1}$ \\
\hline
\end{tabular}


Table 2: Genetic characterization of four polymorphic microsatellite loci isolated from individuals of Nacella magellanica collected from Seno Otway and the Central Magellan Strait region. $\mathrm{N}_{\mathrm{a}}$ Number of alleles, $\mathrm{T}_{\mathrm{a}}$ annealing temperature, $\mathrm{H}_{\mathrm{o}} / \mathrm{H}_{\mathrm{e}}$ observed and expected Heterozygosity, PI probability of identity. Violations of Hardy Weinberg

Equilibrium are shown in bold numbers (Bonferroni corrected 5\% significant level $=0.00714$ )

\begin{tabular}{|c|c|c|c|c|c|c|c|c|c|c|c|c|}
\hline Locus & Primer sequence $\left(5^{\prime}-3^{\prime}\right)$ & Dye & repeat motif & $\mathbf{N}_{\mathrm{a}}$ & $\begin{array}{c}\text { Size } \\
\text { range } \\
\text { (bp) } \\
\end{array}$ & $\begin{array}{c}\mathbf{T}_{\mathbf{a}} \\
\left({ }^{\circ} \mathbf{C}\right) \\
\end{array}$ & $\mathbf{n}$ & $\mathbf{H}_{\mathbf{0}} / \mathbf{H}_{\mathrm{e}}$ & PI (unbiased) & $\mathbf{n}$ & $\mathbf{H}_{\mathbf{o}} / \mathbf{H}_{\mathrm{e}}$ & PI (unbiased) \\
\hline Nma3 & $\begin{array}{l}\text { F: ATG AAT CAA AAC TGT } \\
\text { TGG CT } \\
\text { R: TGC GCT ATG ACA TAC } \\
\text { ACA TT }\end{array}$ & Hex & $(\mathrm{C})_{14}(\mathrm{CA})_{14}$ & 25 & $189-220$ & 57 & 31 & $0.81 / 0.88$ & $1.854 \times 10^{-2}$ & 46 & $0,83 / 0.87$ & $2,348 \times 10-2$ \\
\hline Nma4 & $\begin{array}{l}\text { F: ATC TCC GCA GAT ACA } \\
\text { AAC AA } \\
\text { R: GGG TAT TGG TGA GAT } \\
\text { GTG TT }\end{array}$ & Fam & $(\mathrm{CA})_{7} \mathrm{CG}(\mathrm{CA})_{3}$ & 17 & $184-202$ & 57 & 31 & $0.77 / 0.89$ & $1.827 \times 10^{-2}$ & 46 & $0,83 / 0.89$ & $1,682 \times 10-2$ \\
\hline Nma6 & $\begin{array}{l}\text { F: CTT TAG CAA AAT TGG } \\
\text { TTT CG } \\
\text { R: GGC AGG TTT GAC AGC }\end{array}$ & Hex & $(\mathrm{CT})_{5} /(\mathrm{CT})_{2} \mathrm{GT}(\mathrm{CT})_{3} \mathrm{GT}(\mathrm{CT})_{2} /$ & 57 & $192-324$ & 57 & 31 & $0.84 / 0.97$ & $3.036 \times 10^{-4}$ & 45 & $0,73 / 0.95$ & $2,975 \times 10-3$ \\
\hline Nma12 & $\begin{array}{l}\text { TAA T } \\
\text { F: TGT CAT CCG TCA AAA } \\
\text { TGT TA } \\
\text { R: TCT TCA ATG AGA CAA } \\
\text { AAC CC }\end{array}$ & Fam & $(\mathrm{CT})_{6} \mathrm{TG}(\mathrm{CT})_{21} /(\mathrm{CT})_{5}$ & 28 & $177-235$ & 57 & 29 & $0.83 / 0.95$ & $2.948 \times 10^{-3}$ & 44 & $0,75 / 0.94$ & $4,400 \times 10-3$ \\
\hline
\end{tabular}


Table 3: Cross amplification tests of the eight isolated microsatellite loci. The loci isolated from Nacella magellanica were cross tested with individuals of Nacella deaurata and vice versa. All eight loci were tested for cross amplification with individuals of Nacella delicatissima and Nacella mytilina

\begin{tabular}{cccc} 
Locus & $\begin{array}{c}\text { Nacella } \\
\text { magellanica }\end{array}$ & Nacella deaurata & Nacella mytilina \\
\hline \hline Nma3 & $189-220$ & not amplified & not amplified \\
Nma4 & $184-202$ & $187-205$ & $191-203$ \\
Nma6 & $192-324$ & $186-318$ & $190-198$ \\
Nma12 & $177-235$ & not amplified & not amplified \\
Nde1 & $210-246$ & $213-234$ & $210-235$ \\
Nde2 & not amplified & $154-218$ & $168-194$ \\
Nde3 & $260-280$ & $260-276$ & 260 \\
Nde8 & $108-147$ & $108-151$ & $125-150$ \\
\hline
\end{tabular}

References

De Aranzamendi CM, Gardenal CN, Martin JP, Bastida R (2009) Limpets of the genus Nacella

(Patellogastropoda) from the southwestern Atlantic: species identification based on molecular data, Journal of Molluscan Studies, 00: 1-11.

Excoffier L, Laval G, Schneider S (2005) Arlequin v 3.5: an integrated software package for population genetics data analysis. Evolutionary Bioinformatics Online, 1: 47-50.

González PM, Malanga G, Puntarulo S (2008) Ferritin and labile iron pool in limpets from the Beagle Channel. In Svensson EP (Ed.) Aquatic Toxicology Research Focus, pp 177-188.

Held C, Leese F (2007) The utility of fast evolving molecular markers for studying speciation in the Antarctic benthos. Polar Biology, 30: 513-521.

Kraemer L, Beszteri B, Gäbler-Schwarz S, Held C, Leese F, Mayer C, Pöhlmann K, Frickenhaus S (2009)

STAMP: Extentions to the STADEN sequence analysis package for high throughput interactive microsatellite marker design. BMC Bioinformatics, 10:41.

Krawetz S and Misener S (Eds.) Bioinformatics Methods and Protocols: Methods in Molecular Biology. Totowa, NJ, Humana Press.

Malanga G, Estevez MS, Calvo J, Abele D, Puntarulo S (2005) Oxidative stress in gills of limpets from the Beagle Channel: comparison with limpets from the Antarctic. Scientia Marina, 69 (Suppl 2): 297-304.

Malanga G, Estevez MS, Calvo J, Puntarulo S (2004) Oxidative stress in limpets exposed to different environmental conditions in the Beagle Channel. Aquatic Toxicology, 69: 299-309.

Mayer C (2008) Phobos, a Tandem Repeat Search Tool for Complete Genomes. http://www.ruhr-unibochum.de/spezzoo/cm/cm phobos.htm

Nolte AW, Stemshorn KC, Tautz D (2005) Direct cloning of microsatellite loci from Cottus gobio through a simplified enrichment procedure. Molecular Ecology Notes, 5: 628- 636.

Rousset F (2008) GENEPOP '007: a complete re-implementation of the GENEPOP software for Windows and Linux. Molecular Ecology Resources, 8(1): 103-106.

Rice (1989) Analyzing tables of statistical tests. Evolution 43(1): 223-225 
Rozen S, Skaletsky HJ (2000) Primer3 on the WWW for general users and for biologist programmers. In Staden R (1996) The Staden Sequence Analysis Package. Molecular Biotechnology, 5: 233- 241.

Valdovinos C, Rüth M (2005) Nacellidae limpets of the southern end of South America: taxonomy and distribution. Revista Chilena de Historia Natural, 78: 497-517.

Valiere N (2002) GIMLET: a computer program for analysing genetic individual dentification data. Molecular Ecology Notes, 2: 377-379.

Van Oosterhout C, Hutchinson WF, Willis DPM, Shipley P (2004) MICRO- CHECKER: software for identifying and correcting genotyping errors in microsatellite data. Molecular Ecology, 4: 535-538. 